\title{
The severe acute respiratory syndrome coronavirus in tears
}

\author{
S-C Loon, S C B Teoh, L L E Oon, S-Y Se-Thoe, A-E Ling, Y-S Leo
}

Br J Ophthalmol 2004;88:861-863. doi: 10.1136/bjo.2003.035931

\begin{abstract}
Background: Severe acute respiratory syndrome (SARS) is a new infectious disease that caused a global outbreak in 2003. Research has shown that it is caused by a novel coronavirus. A series of cases is reported where polymerase chain reaction (PCR) testing on tears had demonstrated the presence of the virus. Detection of ocular infection from tears using the PCR technique has been widely used by ophthalmologists to diagnose infections for other viruses.

Methods: This is a case series report from cases classified as probable or suspect SARS cases. Tear samples were collected from 36 consecutive patients who were suspected of having SARS in Singapore over a period of 12 days (7-18 April 2003), and analysed by PCR using protocols developed by the WHO network of laboratories.

Results: Three patients with probable SARS (one female and two male patients) had positive results from their tear samples. Tear samples were used to confirm SARS in the female patient, who was positive only from her tears. The positive specimens were found in cases sampled early in their course of infection.

Conclusions: This is the first case series reported with the detection of the SARS coronavirus from tears, and has important implications for the practice of ophthalmology and medicine. The ability to detect and isolate the virus in the early phase of the disease may be an important diagnostic tool for future patients and tear sampling is both simple and easily repeatable. Many healthcare workers are in close proximity to the eyes of patients and this may be a source of spread among healthcare workers and inoculating patients. Ophthalmic practices may need to change as more stringent barrier methods, appropriate quarantine, and isolation measures are vital when managing patients with SARS.
\end{abstract}

$\mathrm{S}$ evere acute respiratory syndrome (SARS) is a recent disease that had a significant worldwide impact both in mortality and economic morbidity. Initial reports established from blood and respiratory samples show that the disease is caused by a novel strain of coronavirus. ${ }^{12}$ The natural course of the disease has been shown to have an incubation period of 2-7 days, preceded by a prodrome of pyrexia $\left(38.0^{\circ} \mathrm{C}\right.$ or more) and may be associated with chills, rigors, malaise, myalgia, dry cough, dyspnoea, or headache. ${ }^{3}$

Singapore was one of the countries adversely affected by SARS. The index patients presented in early March 2003 and by the end of the outbreak on 31 May 2003, 238 probable cases were diagnosed. In an effort to identify patients early at a time when diagnostic kits were still under investigation around the world, we collected specimens from various secretions, including tears from patients diagnosed with SARS. ${ }^{3}$ Detection of ocular infection from tears using the polymerase chain reaction (PCR) technique has been widely used by ophthalmologists to diagnose infections especially of the herpesviridae family, such as the herpes simplex virus types 1 and 2, ${ }^{4-6}$ Epstein-Barr virus, ${ }^{7}$ varicella zoster virus, and human herpes virus $6 .{ }^{8}$ Other viruses that been identified and genotyped from tears with this technique include hepatitis $\mathrm{C},{ }^{9-11}$ hepatitis $\mathrm{B},{ }^{12}$ measles, ${ }^{13}$ and adenovirus. ${ }^{14}$ Tears PCR has even been used to diagnose Acanthamoeba keratitis, ${ }^{15}$ an infection which often poses diagnostic dilemmas to the ophthalmologist.

Finding the SARS coronavirus in tears is important, as the latter may be a potential source of spread. This is the first recorded case series of detection of the SARS coronavirus from tears.

\section{METHODS}

Patients who presented with symptoms of SARS from the period 11-18 April 2003 at Tan Tock Seng Hospital were included in the study. Probable and suspect cases were defined according to WHO case definitions. ${ }^{16}$ Suspect patients were those presenting with fever of more than $38.0^{\circ} \mathrm{C}$, respiratory symptoms and history of contact with a case of probable SARS, or were in an affected institution for which alternative diagnoses had been excluded. Probable cases were suspect cases with chest radiograph changes compatible with pneumonia or acute respiratory distress syndrome.

Patients were identified for sample collection once they met the case definitions for probable and suspect SARS. The patient's signed consent was obtained for each sample collection. Tear samples were collected by conjunctival swab technique. Eyelids were everted and samples were obtained by sweeping the inferior fornices of both eyes with sterile cotton tipped swabs without topical anaesthesia. The tips of the swab sticks were broken off and placed into Hank's balanced salt solution. Gloves were changed when collecting specimens in between patients to minimise risk of contamination. Samples were transported in ice to the WHO network laboratory in the virology section of the Department of Pathology at the Singapore General Hospital.

\section{Reverse transcription-polymerase chain reaction}

All samples were subject to RNA extraction followed by conventional qualitative reverse transcription-polymerase chain reaction (RT-PCR) with two sets of primers. The primers were targeted at different regions of the polymerase (pol) gene of the SARS coronavirus, which is one of the most conserved sites of the virus genome. The RT-PCR protocols were developed by the WHO network of laboratories ${ }^{17}$ and are summarised in table 1. RNA extraction was carried out using the viral RNA kit (QIAamp, Qiagen, Australia) from $200 \mu \mathrm{l}$ of the Hank's solution in which the swab was immersed. A volume of $6 \mu \mathrm{l}$ of extracted RNA was used to generate cDNA using SuperScript II RNase H-reverse transcriptase (Invitrogen). A $20 \mu \mathrm{l}$ reaction volume of RT mix (containing $6 \mu \mathrm{l}$ viral RNA extract, $250 \mathrm{ng}$ of random primers (PdN6), Abbreviations: PCR, polymerase chain reaction; SARS, severe acute
respiratory syndrome 
$250 \mathrm{mM}$ dNTP mix, 0.01M DTT, 40 units ribonuclease inhibitor, and 200 units SuperScript II RT Rnase in IX first strand buffer) was prepared. The RT mix was then incubated at $42^{\circ} \mathrm{C}$ for 50 minutes and $70^{\circ} \mathrm{C}$ for 15 minutes. The cDNA generated was subjected to PCR using two sets of primers. The PCR products were then analysed using a $2 \%$ agarose gel.

A positive result with either set of primers on the first round of RT-PCR had to be confirmed by re-extracting the RNA from the original sample and subjecting the sample to a second round of RT-PCR with both sets of primers. The result would be reported as positive in these circumstances: (1) if a positive result is obtained with both sets of primers, or (2) if one set of primers is positive and there was a positive PCR result from another sample type from the same patient.

Results and patient data were tabulated on an Excel worksheet and analysed using SPSS statistical software (vll.0) (Chicago, IL, USA). Differences in means were compared using the Student's $t$ test. p Values of less than 0.05 were considered statistically significant.

\section{RESULTS}

Samples were collected from 36 patients initially suspected to have SARS over a period of 12 days (7-18 April 2003), 17 of whom were male and 19 were female patients. The majority were healthcare workers and female nurses. Using WHO case definitions, eight patients were eventually proved to be probable SARS (later confirmed by serology) and the other 28 were SARS suspects. Of the eight probable SARS, there were four males and four females. Mean age was 48.6 (SD 21.8) years (range 25-85 years, males 61.5 (22.9) years, females 35.8 (11.7) years). Tear samples from three probable SARS patients $(37.5 \%)$ yielded positive PCR results, while none of the SARS suspect patients had a positive PCR result. Table 2 gives the profile of the three cases with SARS coronavirus RNA detected in their tears. Two were elderly male patients with multiple co-morbidities, while the third was a young female healthcare worker who had the virus detected only in her tears by current PCR kits.

All three positive cases had their tears sampled in the early phase (within 9 days of onset) of their illness (mean 4.0 (3.2) days). The other five probable SARS cases who had negative yield were sampled in the later part of their illness (mean 19.4 (11.2) days), although the difference did not reach statistical significance $(\mathrm{p}=0.08)$.

\section{DISCUSSION}

In our small series, we have demonstrated the presence of viral RNA in the tears. Ophthalmologists examine patients at close distances and inadvertent physical contact with patients' eyes is inevitable. This is a potential hazard to healthcare workers in close contact with the face and specifically the eyes of SARS patients. There is a potential possibility of transmission to other patients through the use of reusable eye equipment such as the Goldmann applanation tonometer, trial contact lenses, trial frames, and even reusable pinhole devices which come in close contact with the patient's eyes. Our hands may also be a means of inoculating other patients. Splashing of infected body fluids onto the eyes has been a documented mode of infection even for viruses that are not usually spread by mere contact-for example, hepatitis B. ${ }^{18}$ Thus, stringent barrier methods using the "M3G" (mask, gown, gloves, and goggles) should be the gold standard when dealing with suspected SARS patients. Increased vigilance to prevent spread to other eye patients through thorough meticulous disinfection of eye equipment is of crucial importance in breaking the chain of transmission as is maintaining strict hygiene of our routine outpatient procedures and practices.

The detection of the viral RNA by PCR may be a useful adjunct in early diagnosis of SARS and this may have important applications in commencing early treatment and appropriate supportive measures which may have better prognosis for the patient, as well as the institution of appropriate quarantine measures for contacts of this case. Moreover, tear sampling can be performed easily, painlessly, and repeatedly on the slit lamp or by the bedside without discomfort to the patient.

Our study was limited by a small sample size. Ophthalmologists may be a better choice of personnel in the collection of specimens as they are more familiar with tear sampling. Although precautions were taken, contamination from the upper respiratory tract cannot be ruled out. The negative results in the other cases may be due to differences in volume of fluid collected, the collection technique, or the

Table 1 PCR primers, reagent concentrations, and thermal cycling conditions used

\begin{tabular}{|c|c|c|c|c|}
\hline Primer (source) & Primer sequence & $\begin{array}{l}\text { Expected fragment } \\
\text { size }\end{array}$ & PCR reagent formulation* & Thermal cycling profile \\
\hline $\begin{array}{l}\text { Sars1S/As } \\
\text { (Germany) }\end{array}$ & $\begin{array}{l}\text { Sars } 1 S \\
5^{\prime} \text {-cctctcttgitcttgctcgca-3' } \\
\text { SarlAS } \\
\text { 5'-tatagtgagccgccacacatg-3' }\end{array}$ & $121 \mathrm{bp}$ & $\begin{array}{l}5 \mu \mathrm{l} 10 \mathrm{XPCR} \text { buffer } \\
1.5 \mathrm{mM} \mathrm{MgCl} \\
250 \mathrm{mM} \text { of each dNTP } \\
20 \mu \mathrm{M} \text { each primer } \\
2 \text { units of Taq polymerase } \\
2 \mu \mathrm{l} \text { of cDNA } \\
50 \mu \mathrm{l} \text { total volume }\end{array}$ & $\begin{array}{l}\text { Hold: } 95^{\circ} \mathrm{C} / 3 \mathrm{~min} \\
10 \mathrm{cycles} \text { : } \\
95^{\circ} \mathrm{C} / 10 \mathrm{~s} \\
58^{\circ} \mathrm{C} / 10 \mathrm{~s} \\
72^{\circ} \mathrm{C} / 20 \mathrm{~s} \\
40 \mathrm{cycles} \text { : } \\
95^{\circ} \mathrm{C} / 10 \mathrm{~s} \\
56^{\circ} \mathrm{C} / 10 \mathrm{~s} \\
72^{\circ} \mathrm{C} / 20 \mathrm{~s} \\
\text { Hold: } 72^{\circ} \mathrm{C} / 5 \mathrm{~min}\end{array}$ \\
\hline $\begin{array}{l}\text { Corl / } 2 \\
\text { (Hong Kong) }\end{array}$ & $\begin{array}{l}\text { Cor } 1 \\
\text { 5'-caccgtttctacaggttagctaacga-3' } \\
\text { Cor2 } \\
\text { 5'-aaatgtttacgcacggtaagcgtaaaa-3' }\end{array}$ & $310 \mathrm{bp}$ & & $\begin{array}{l}\text { Hold: } 94^{\circ} \mathrm{C} / 2 \mathrm{~min} \\
10 \mathrm{cycles} \text { : } \\
94^{\circ} \mathrm{C} / 30 \mathrm{~s} \\
56^{\circ} \mathrm{C} / 60 \mathrm{~s} \\
70^{\circ} \mathrm{C} / 45 \mathrm{~s} \\
35 \mathrm{cycles}: \\
94^{\circ} \mathrm{C} / 30 \mathrm{~s} \\
60^{\circ} \mathrm{C} / 45 \mathrm{~s} \\
70^{\circ} \mathrm{C} / 45 \mathrm{~s} \\
\text { Hold: } 72^{\circ} \mathrm{C} / 5 \mathrm{~min}\end{array}$ \\
\hline
\end{tabular}


Table 2 Profile of cases with PCR test positive for SARS coronavirus

\begin{tabular}{|c|c|c|c|}
\hline & \multicolumn{3}{|l|}{ Case } \\
\hline & 1 & 2 & 3 \\
\hline Age & 30 & 74 & 85 \\
\hline Sex & $\mathrm{F}$ & $M$ & M \\
\hline \multicolumn{4}{|l|}{ Details of admission } \\
\hline Onset & 8 April 03 & 2 April 03 & 14 April 03 \\
\hline Date of admission & 9 April 03 & 7 April 03 & 14 April 03 \\
\hline Date of first abnormal CXR & 14 April 03 & 11 April 03 & 14 April 03 \\
\hline Outcome & Discharged well & Dead & Dead \\
\hline Date of death or discharge & 23 April 03 & 23 April 03 & 18 April 03 \\
\hline Remarks & $\begin{array}{l}\text { Healthcare worker } \\
\text { infected by case } 2\end{array}$ & $\begin{array}{l}\text { Inpatient from } 29 \text { March } \\
03 \text { for subacute } 10\end{array}$ & $\begin{array}{l}\text { Inpatient for cholecystitis. } \\
\text { Infected by sibling of the } \\
\text { index case in SGH }\end{array}$ \\
\hline \multicolumn{4}{|l|}{ Key laboratory indicators } \\
\hline Total white count $\left(4.0-10.0 \times 10^{9} / \mathrm{l}\right)$ & 8.0 & 4.0 & 6.5 \\
\hline Lymphocyte count $(18-43 \%)$ & 18.9 & 12.0 & 4.4 \\
\hline Platelet count $\left(160-340 \times 10^{9} / \mathrm{l}\right)$ & 275 & 144 & 82 \\
\hline $\begin{array}{l}\text { Lactose dehydrogenase }(200-500 \mathrm{U} / \mathrm{l}) \\
\text { SARS yirus RNA from }\end{array}$ & 283 & 540 & 955 \\
\hline SARS virus RNA from & & & \\
\hline Tears & Positive & Positive & Positive \\
\hline Stools & Negative & Positive & Positive \\
\hline Nasal aspirate & Not sent & Not sent & Positive \\
\hline Date of collection of tears for PCR & 11 April 03 & 11 April 03 & 18 April 03 \\
\hline Day of collection from onset of fever & Day 3 & Day 9 & Day 4 \\
\hline
\end{tabular}

timing of sampling. We propose the use of microcapillary pipettes or Schirmer's filter paper strips that allow collection of cellular material for electron microscopy and immunofluorescence.

We should also determine if the virus is also present in convalescent patients and to determine the infectiousness of tears. As all three positive cases had sampling performed early in the course of their illness, we hypothesise that the secretion of virus in tears occurs only during the early phase of this disease. Even as the epidemic has died down, we are warned of future outbreaks. This may be a simple tool in identifying probable cases in future and prospective trials are being designed for this purpose.

This study also suggests that SARS, like other viruses, can involve the eyes. An ocular review of convalescent probable SARS patients will show if this coronavirus causes any long term abnormalities and pathology to the ocular surface and retina. Results will be reported in due course.

\section{ACKNOWLEDGEMENTS}

We acknowledge the help of the Publicity Support Unit of the National University Hospital, Singapore, in preparing this manuscript.

\section{Authors' affiliations}

S-C Loon, S C B Teoh, The Eye Institute, Tan Tock Seng Hospital, 11 Jalan Tan Tock Seng, Singapore 308433, Republic of Singapore

H-N Leong, Department of Infectious Disease, Singapore General Hospital, Outram Road, Singapore 169608

L L E Oon, S-Y Se-Thoe, A-E Ling, Department of Pathology, Virology Section, Blk 8, Singapore General Hospital, Outram Road, Singapore 169608

Y-S Leo, Centre for Communicable Diseases, Tan Tock Seng Hospital, 11 Jalan Tan Tock Seng, Singapore 308433

Correspondence to: Dr S-C Loon, Department of Ophthalmology, 5 Lower Kent Ridge Road, Main building Level 3, National University Hospital, Singapore 119074; ploonsc@yahoo.com

Accepted for publication 4 December 2003

\section{REFERENCES}

1 Poutanen SM, Low DE, Henry B, et al. Identification of severe acute respiratory syndrome in Canada. N Engl J Med 2003;348:1995-2005 [epub 2003 Mar 31].

2 Drosten C, Günther S, Preiser W, et al. Identification of a novel coronavirus in patients with severe acute respiratory syndrome. N Engl J Med 2003;348: 1967-76 [epub 2003 Apr 10].

3 CDC SARS Investigative Team. Outbreak of severe acute respiratory syndrome-worldwide 2003. MMWR 2003;52:241-8 (www.cdc.gov/ $\mathrm{mmwr} / \mathrm{PDF} / \mathrm{wk} / \mathrm{mm} 5212$.pdf).

4 Koizumi N, Nishida K, Adachi W, et al. Detection of herpes simplex virus DNA in atypical epithelial keratitis using polymerase chain reaction. Br J Ophthalmol 1999;83:957-60.

5 Robert PY, Traccard I, Adenis JP, et al. Multiplex detection of herpes viruses in tear fluid using the "stair primers" PCR method: prospective study of 93 patients. J Med Virol 2002;66:506-11

6 Hidalgo F, Melón S, de Oña M, et al. Diagnosis of herpetic keratoconjunctivitis by nested polymerase chain reaction in human tear film. Eur J Clin Microbiol Infect Dis 1998;17:120-3.

7 Willoughby CE, Baker K, Kaye SB, et al. Epstein-Barr virus (types 1 and 2) in the tear film in Sjögren's syndrome and HIV infection. J Med Virol 2002;68:378-83.

8 Pitkäranta A, Piiparinen H, Mannonen L, et al. Detection of human herpesvirus 6 and varicella-zoster virus in tear fluid of patients with Bell's palsy by PCR. J Clin Microbiol 2000;38:2753-5.

9 Feucht HH, Polywka S, Zöllner B, et al. Greater amount of HCV-RNA in tears compared to blood. Microbiol Immunol 1994;38:157-8.

10 Feucht HH, Zöllner B, Schröter $M$, et al. Tear fluid of hepatitis $C$ virus carriers could be infectious. J Clin Microbiol 1995;33:2202-3.

11 Mendel I, Muraine M, Riachi G, et al. Detection and genotyping of the hepatitis C RNA in tear fluid from patients with chronic hepatitis C. J Med Virol 1997;51:231-3.

12 Su CS, Bowden S, Fong LP, et al. Detection of hepatitis B virus DNA in tears by polymerase chain reaction. Arch Ophthalmol 1994;112:621-5.

13 Shinoda K, Kobayashi A, Higashide T, et al. Detection of measles virus genomic RNA in tear samples from a patient with measles keratitis. Cornea 2002;21:610-2.

14 Dalapathy S, Lily TK, Roy S, et al. Development and use of nested polymerase chain reaction (PCR) for the detection of adenovirus from conjunctivitis specimens. J Clin Virol 1998;11:77-84.

15 Lehmann OJ, Green SM, Morlet N, et al. Polymerase chain reaction analysis of corneal epithelial and tear samples in the diagnosis of Acanthamoeba keratitis. Invest Ophthalmol Vis Sci 1998;39:1261-5.

16 World Health Organization. Case definitions for surveillance of severe acute respiratory syndrome (SARS) (www.who.int/csr/sars/casedefinition/en).

17 World Health Organization. PCR primers for SARS developed by WHO Network Laboratories (www.who.int/csr/sars/primers/en) (accessed 1 May 2003).

18 Su CS, Bowden S, Fong LP, et al. Current tonometer disinfection may be inadequate for hepatitis B virus. Arch Ophthalmol 1994;112:1406-7. 


\section{PostScript}

\section{LETTERS}

If you have a burning desire to respond to a paper published in BJO, why not make use of our "rapid response" option?

Log onto our website (www.bjophthalmol. com), find the paper that interests you, and send your response via email by clicking on the "eletters" option in the box at the top right hand corner.

Providing it isn't libellous or obscene, it will be posted within seven days. You can retrieve it by clicking on "read eletters" on our homepage.

The editors will decide as before whether to also publish it in a futher paper issue.

\section{Potential diagnostic dilemmas using the multifocal electroretinogram in intermittent exotropia}

Multifocal electroretinography (mfERG) is a valuable technique in assessing macular function in retinal disease objectively as it provides spatial information. Altered responses give an estimate of the extent of central retinal dysfunction. ${ }^{1-4}$ Fixation is known to be an important technical factor in mfERG recording. ${ }^{5-7}$ We present findings in a patient with asymptomatic intermittent exotropia that reinforce the importance of adequate consideration of potential fixation errors.

\section{Case report}

The patient was a 52 year old man with maternally inherited diabetes and deafness (MIDD) consequent upon a mitochondrial DNA nucleotide A3243G point mutation, and examined as part of a series of patients with MIDD. ${ }^{8}$ Visual acuity was 20/20 (ETDRS chart) bilaterally. Fundi showed symmetrical bilateral irregular patches of retinal pigment epithelium atrophy at the posterior poles. The foveas were normal.

Macular function was assessed initially by mfERG recorded binocularly with a stimulus size of 61 hexagons using the RETIscan System (Roland Consult, Wiesbaden, Germany). The patient fixated on the centre of a large diagonal cross, centred over the central hexagon, at a viewing distance of $33 \mathrm{~cm}$. Pupils were dilated. Refractive errors were corrected with -6.25 dioptres (D) right eye and -6.25 spherical dioptres combined with -0.75 cylindrical dioptres at $5^{\circ}$ left eye. Additional $+3 \mathrm{D}$ were given for a viewing distance of $33 \mathrm{~cm}$. Each recording session consisted of eight trials over about 20 minutes.

Upon binocular recording, changes reflecting the retinal dystrophy were visible in the right eye trace array outside the central hexagon. The normal foveal response was consistent both with normal foveal function and central fixation throughout testing (fig 1A). Amplitude reduction was observed in many left eye traces with an additional "off centre" peak also visible in three dimensional plot (fig 1B). These findings are not suggestive of MIDD. The mfERG was repeated monocularly. The left eye findings now showed a normal central response and alterations in parafoveal function consistent with MIDD (figs $2 \mathrm{~A}, \mathrm{~B}$ ).

Subsequent orthoptic examination revealed a near type intermittent exotropia with poor motor fusion and additional microtropia. The latent deviation of the left eye was 2 prism dioptres base-in at 6 metres and 18 prism dioptres base-in at $33 \mathrm{~cm}$. A small vertical height component was demonstrated on the Hess chart. Stereopsis was subnormal.

\section{Comment}

Patients with intermittent exotropia can be completely controlled having binocular vision or may have a manifest exotropia." Under binocular mfERG stimulation, the left eye presumably fixated in exotropia at times of fusional decompensation, and the stimulus pattern shifted by the extent of the squint deviation. At times of positive binocular vision the fixation was located almost centrally. The fixation was slightly shifted

\section{A}

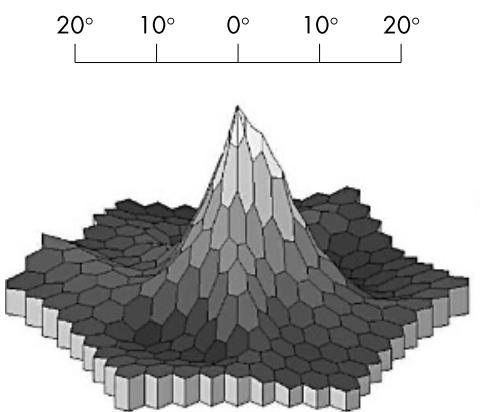

$\mathrm{RE}$, binocular because of the microtropia (fig 1B) which was not detected by direct observation.

Examiners should always be aware that not only retinal disease can affect the mfERG. Asymptomatic strabismus is a reason for dilemma in the interpretation of binocular mfERGs. Even with direct observation a small intermittent strabismus may be not be detected. This could result in a broadened central peak rather than the double peak for macular dysfunction. This would be potentially disastrous in a patient with optic nerve disease where the MfERG should be normal. ${ }^{2}$

C Bellmann, M M Neveu, L Kousoulides, J J Sloper, A C Bird, G E Holder Moorfields Eye Hospital, London, UK

Correspondence to: G Holder, PhD, Department of Electrophysiology, Moorfields Eye Hospital, City Road, London ECIV 2PD, UK; graham.holder@ moorfields.nhs.uk

doi: $10.1136 /$ bjo.2003.040584

Accepted for publication 31 January 2004 fixation instability and represents a potential seen in our patient and thus be mistaken

B

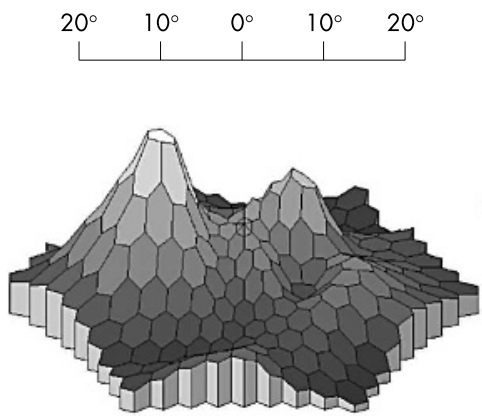

$\mathrm{LE}$, binocular

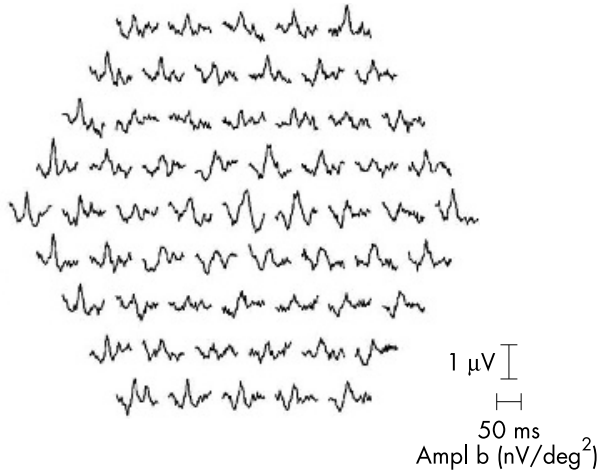

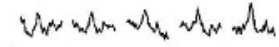
Whe ver vin whe wow whe

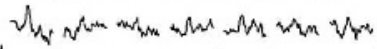

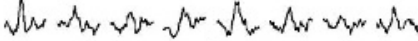

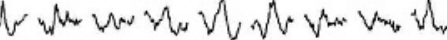

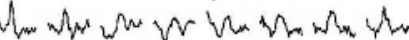

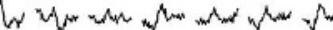
Mor when wher $1 \mu \mathrm{V} I$ Ampl b (nV/deg $\left.{ }^{2}\right)$
Figure 1 (A) Three dimensional plot (left) and trace arrays (right) of the right eye recorded binocularly. See text for details. (B) Left eye under binocular recording. On the three dimensional plot (left) the left peak is consistent with fixation in exotropia. At times of positive binocular vision the fixation is almost centrally located (right peak). Trace array changes are seen in most hexagons (right). 
A

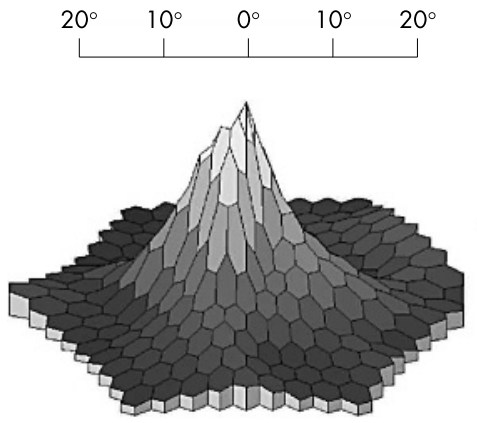

$\mathrm{RE}$, monocular

B

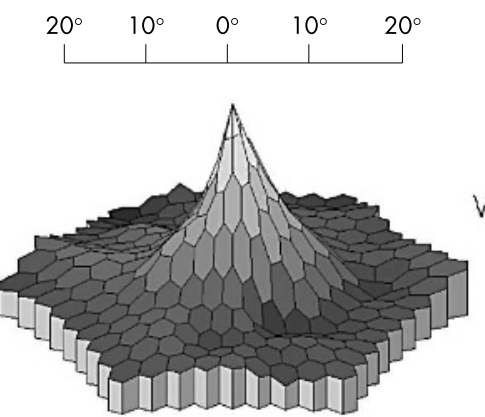

$L E$, monocular

$$
\begin{aligned}
& \text { Mn ar an Ma }
\end{aligned}
$$

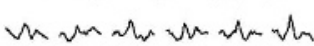

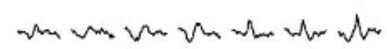

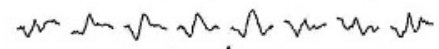

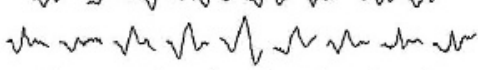

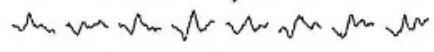

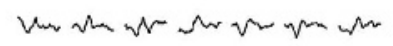

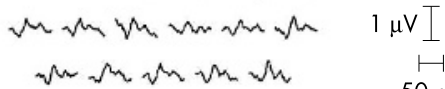

$$
\begin{aligned}
& 50 \mathrm{~ms}
\end{aligned}
$$

Ampl b (nV/deg $\left.{ }^{2}\right)$

Figure 2 (A) Monocular mfERG recording of the right eye. (B) Monocular mfERG recording of the left eye. Changes reflecting MIDD are visible outside the central hexagon.

Supported by the European Commission No QLK6CT2000-51262 (Marie Curie Individual Fellowship) and by the Faun-Foundation to $C B$.

We thank Roland Consult for mfERG facilities.

\section{References}

1 Sutter EE, Tran D. The field topography of ERG components in man $-\mathrm{I}$. The photopic luminance response. Vis Res 1992;32:433-46.

2 Hood DC. Assessing retinal function with the multifocal technique. Prog Retin Eye Res 2000; 19:607-46.

3 Kretschmann U, Bock M, Gockeln R, et al. Clinical applications of multifocal electroretinography. Doc Ophthalmol 2000;100:99-113.

4 Palmowski AM, Sutter EE, Bearse MA, et al. Mapping retinal function in diabetic retinopathy using the multifocal electroretingram. Invest Ophthalmol Vis Sci 1997;38:2586-96.

5 Keating D, Parks S, Evans AL. Technical aspects of multifocal ERG recording. Doc Ophthalmol 2000;100:77-98.

6 Chisholm JA, Keating D, Parks S, et al. The impact of fixation on the multifocal electroretinogram. Doc Ophthalmol 2001;102:131-9.

7 Rudolp G, Kalpadakis P. The role of fixation for reliable mfERG results. Graefes Arch Clin Exp Ophthalmol 2002;240:874-5.

8 Bellmann C, Neveu MM, Scholl HPN, et al. AU provide title of abstract. Invest Ophthalmol Vis Sci 2003;45:ARVO E-Abstract 530.

9 Rutstein RP, Corliss DA. The clinical course of intermittent exotropia. Optom Vis Sci 2003;80:644-9.

\section{Partial resolution of diabetic macular oedema after systemic treatment with furosemide}

Furosemide is a potent diuretic which is an anthranilic acid derivative. Chemically, it is
4-chloro-N-furfuryl-5-sulfamoylanthranilic acid. Furosemide is indicated for the treatment of oedema associated with congestive heart failure, cirrhosis of the liver, and renal disease, including the nephrotic syndrome.

Here I report a case of a diabetic patient, with nephrotic syndrome, who experienced marked improvement in diabetic macular oedema after systemic treatment with furosemide.

\section{Case report}

A 41 year old woman with type II insulin dependent diabetes mellitus was referred for decrease in vision in both eyes over the past 2 months. Besides the diabetes, her past medical history was positive for irregular menstrual cycle and gastroparesis. The patient had also noticed a gain in weight of about $30 \mathrm{lb}(13.5 \mathrm{~kg})$ over the same period of time, from $154 \mathrm{lb}(69.3 \mathrm{~kg})$ to $196 \mathrm{lb}$ $(88.2 \mathrm{~kg})$. She was treated with insulin for the diabetes and Regulin Forte for the irregular menstrual cycle. Her glycosylated haemoglobin was $9.5 \%$.

On examination her best corrected visual acuity (VA) was 20/400 in both eyes. Anterior segment examination was normal. Dilated biomicroscopic examination of the retina of both eyes revealed diffuse macular oedema. There were also a few microaneurysms scattered throughout the posterior pole, but no hard exudates. Fluorescein angiography (FA) examination confirmed the presence of background diabetic retinopathy and demonstrated diffuse leakage in the macula of both eyes (fig 1). Optical coherence tomography (OCT) examination of the macula in both eyes confirmed the presence of macular oedema. The central retinal thickness measured by OCT was $763 \mu \mathrm{m}$ in the right eye and $722 \mu \mathrm{m}$ in the left eye (fig 2A-B). The patient was offered grid laser treatment for the macular oedema, but she did not feel well and she refused the treatment. A follow up appointment was arranged for 3 weeks' time.

The following day the patient presented to the emergency room complaining of nausea and weakness. She was admitted to the hospital with a diagnosis of nephrotic syndrome and fluid overload. Her albuminuria level was $350 \mathrm{mg} / \mathrm{l}$ (normal value <12 mg/l).

She was treated with systemic furosemide $40 \mathrm{mg}$ twice a day for 2 weeks. A few days after starting the treatment with furosemide she began to lose weight. She also noticed an improvement in her vision. In 3 weeks the patient lost $30 \mathrm{lb}(13.5 \mathrm{~kg})$ and she had returned to her usual weight of $154 \mathrm{lb}$ $(69.3 \mathrm{~kg})$. Three weeks later her vision had improved to $20 / 80$ in both eyes. On fundus examination there was marked improvement in the macular oedema in both eyes. OCT examination confirmed the partial resolution of the macular oedema. The central retinal thickness measured by OCT was $250 \mu \mathrm{m}$ in the right eye and $218 \mu \mathrm{m}$ in the left eye (fig 2C, D)

\section{Comment}

Diabetic macular oedema is characterised by hyperpermeability of retinal blood vessels and subsequent formation of hard exudates and macular oedema, the degree of which can be estimated by measurement of retinal thickness. The severity and progression of diabetic macular oedema has been associated with the presence of nephrotic syndrome and to the degree of proteinuria. ${ }^{1-5}$ In a recent
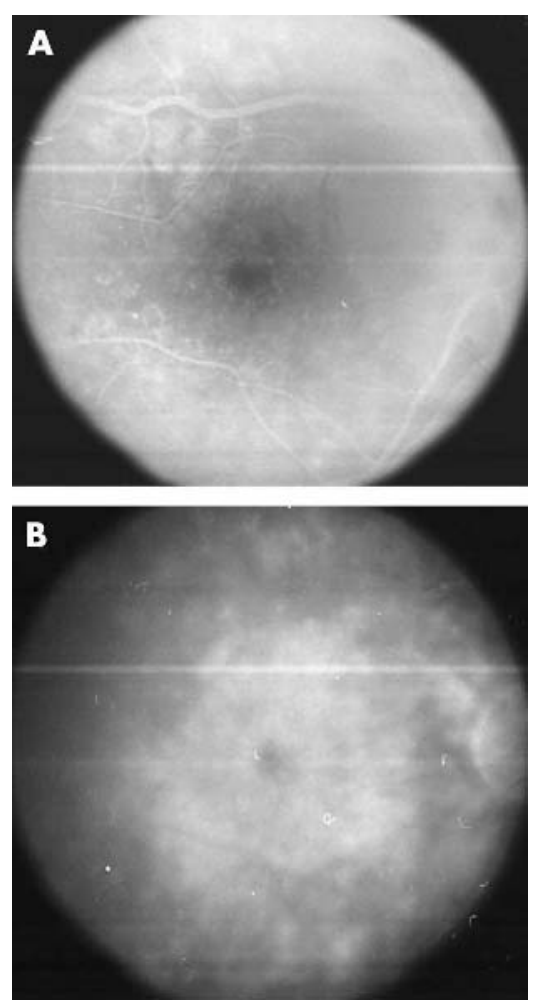

Figure 1 Early (A) and late (B) FA study of the right eye demonstrated diffuse leakage of dye in the macular area consistent with a diagnosis of diffuse diabetic macular oedema. 

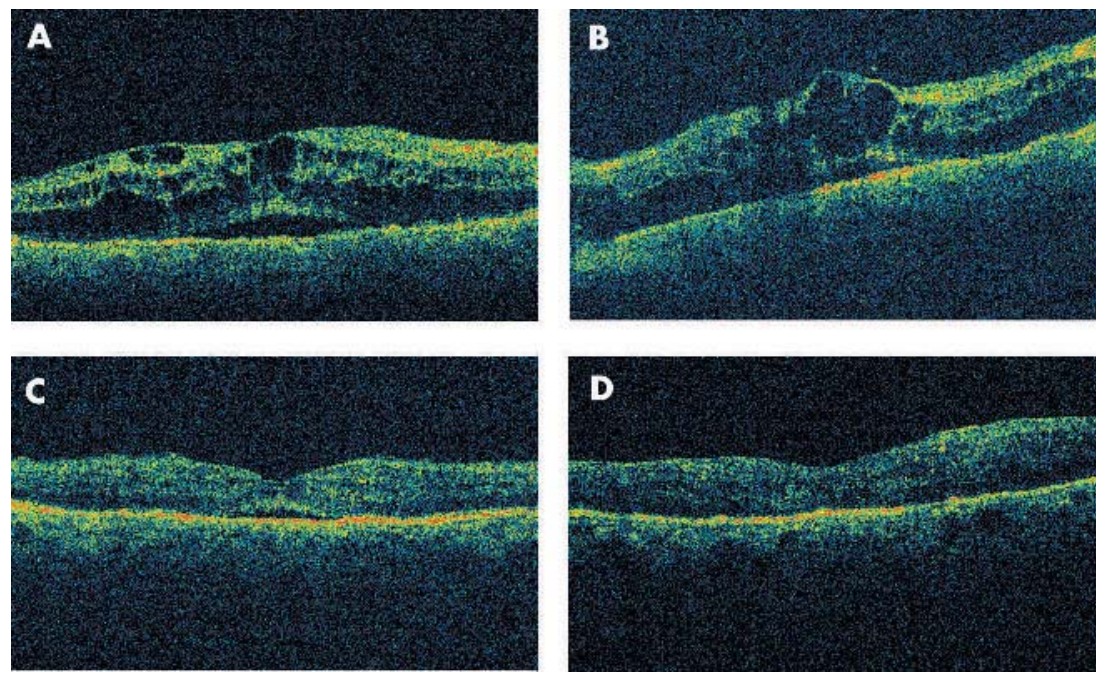

Figure 2 OCT examination of the right eye (A) and of the left eye (B) demonstrates marked thickening of the macula and large, intraretinal, fluid filled, cystoid spaces. Note the presence of a serous elevation of the neurosensory retina in the right eye. (C, D) OCT examination of the right eye (C) and of the left eye (D) of the same patient after systemic treatment with furosemide for 2 weeks demonstrates marked improvement in the macular oedema. There is almost complete resolution of the intraretinal cystoid spaces in both eyes. There is persistence of a small, shallow, subfoveal, serous, neurosensory detachment in the right eye.

study Knudsen et al demonstrated the presence of an association between retinal thickness as evaluated OCT, and glomerular leakage as evaluated by urinary albumin excretion rate in type II diabetic patients with diabetic macular oedema.

Nephrotic syndrome is characterised by massive proteinuria, which leads to hypoproteinaemia/hypoalbuminaemia, hyperlipidaemia with elevated cholesterols, triglycerides and other lipids, and oedema. The oedema results not only from the hypo-osmolar state caused by the loss of plasma proteins, but also from abnormal salt and water retention.

Furosemide is used in the treatment of fluid overload experienced by patients with nephrotic syndrome because it is a potent and rapid acting diuretic. It has been demonstrated that furosemide inhibits primarily the absorption of sodium and chloride not only in the proximal and distal tubules but also in the loop of Henle.

I reported what is, to my knowledge, the first case of marked improvement of diabetic macular oedema after systemic treatment with furosemide documented by OCT examination. I think that the fluid overload secondary to the nephrotic syndrome was the main cause of the worsening of the macular oedema in this patient, and that the intensive treatment with furosemide was responsible for reducing the amount of fluid overload and resolving the macular oedema. The exact mechanism of the action of furosemide in resolving the macular oedema is unknown. Tsuboi et al demonstrated that furosemide inhibits fluid absorption across retinal pigment epithelium (RPE) in an experimental model of retinal detachment in monkeys. ${ }^{6}$ According to their study furosemide could worsen the presence of a neurosensory macular detachment especially in a patient where the subneurosensory retina fluid collection is secondary to a defect in RPE pump. ${ }^{7}$ However, the FA study of this patient at presentation demonstrated multiple retinal microaneurysms at the posterior pole of both eyes and diffuse intraretinal microvascular leakage of dye in the late phase of the study. The FA study was consistent with the appearance of diffuse diabetic macular oedema. In such cases the intraretinal and subneurosensory retina leakage of dye is secondary to a microvascular retinal defect and not to a failure in the RPE pump. I think that restoration of more normal oncotic pressure within the retinal vasculature was the underlying reason for the response to the drug of the diabetic macular oedema.

A P Ciardella

Denver Health Medical Center, Denver, CO; Rocky Mountain Lyon Eye Institute, Aurora, CO, USA

Correspondence to: A P Ciardella, MD, Denver Health Medical Center, 777 Bannock Street, Mail code 0156 , Denver, CO 80204, USA; Antonio.ciardella@ dhha.org

doi: 10.1136/bjo.2004.042580

Accepted for publication 17 March 2004

\section{References}

Klein R, Klein BE, Moss SE, et al. The Wisconsin Epidemiologic Study of Diabetic Retinopathy. IV. Diabetic macular edema. Ophthalmology 1984;91:1464-74.

2 Sinclair SH, Nesler C, Foxman B, et al. Macular edema and pregnancy in insulin-dependent
diabetes. Am J Ophthalmol 1984;97:154-67

3 Agardh CD, Agardh E, Torffvit $O$. The association between retinopathy, nephropathy, cardiovascular disease and long-term metabolic control in type 1 diabetes mellitus: a 5 year follow-up study of 442 adult patients in routine care. Diabetes Res Clin Pract 1997;35:113-21.

4 Klein R, Klein BE, Moss SE, et al. The Wisconsin Epidemiologic Study of Diabetic Retinopathy: $\mathrm{XVII}$. The 14-year incidence and progression of diabetic retinopathy and associated risk factors in type 1 diabetes. Ophthalmology 1998; 105:1801-15.

5 Knudsen ST, Bek T, Poulsen PL, et al. Macular edema reflects generalized vascular hyperpermeability in type 2 diabetic patients with retinopathy. Diabetes Care 2002;25:2328-34.
6 Tsuboi S, Pederson JE XI. Furosemaide inhibitable fluid absorption across retinal pigment epithelium in vivo. Arch Ophthalmol 1986;104:602-3.

7 Spitznas M. Central serous chorioretinopathy. Ophthalmology 1980;87(8S):88.

\section{Vision loss as a complication of gamma knife radiosurgery for trigeminal neuralgia}

Gamma knife radiosurgery has been found useful for treatment of trigeminal neuralgia (TN). ${ }^{1-4}$ Although it is generally safe and well tolerated by most patients, adverse effects have been reported..$^{1-6}$ Potential ocular complications include "dry eye" and "corneal numbness. ${ }^{156}$ We describe a case of vision loss that occurred 9 months after gamma knife radiosurgery for TN.

\section{Case report}

A 68 year old man presented in September 2003 with 3 weeks of fluctuating blurred vision in the right eye. The blurring began 3 weeks earlier and had been preceded by complete numbness of the right side of his face for 1 week.

The patient's medical history was remarkable for right sided TN that began in 1998, predominantly involving the V2 dermatome. It had been managed medically at first but eventually became incapacitating and led to hospital admission.

In December 2002, he had undergone gamma knife radiosurgery (Leksell Gamma Knife; Elekta Inc, Norcross, GA, USA). The dose matrix grid was $0.6 \mathrm{~mm}$ and the right trigeminal root entry zone was targeted tangential to the brainstem. The prescription dose was $40 \mathrm{~Gy}$ to the $50 \%$ isodose line. A single run with a single shot (treatment time, 29.25 minutes) used a $4 \mathrm{~mm}$ collimator. Within days, the patient had clinically significant improvement in symptoms, was pain free, and required no pain medication.

The patient also had a history of chronic renal failure requiring dialysis three times weekly, hypertension, a myeloproliferative disorder, prostate cancer, and hyperlipidaemia. In 1998, he had resection of a left frontal lobe meningioma. His ocular history included bilateral cataract surgery but no history of herpes zoster or herpes simplex.

On initial examination, his vision measured 20/25 right eye and 20/25 left eye. Slit lamp examination of the right cornea revealed a fine punctate epitheliopathy (fig 1A). Corneal sensation, tested with a Cochet-Bonnet aesthesiometer (Luneau Ophtalmologie, Chartres Cedex, France), was absent even at a $5 \mathrm{~mm}$ filament length, both subjectively and by blink reflex. Sensation in the left cornea was present at a $60 \mathrm{~mm}$ filament length.

The patient's vision gradually declined despite treatment with preservative free artificial tears and placement of a punctal plug in the right lower lid. Ten weeks after presentation, his vision measured 20/200 right eye and 20/25 left eye. Slit lamp examination revealed severe epithelial keratopathy in the right eye (fig 1B). Fourteen months after radiosurgery, T2 weighted magnetic resonance imaging showed increased signal intensity in the anterior aspect of the right fifth nerve (fig 2).

A punctal plug was placed in the right upper lid. The patient began using topical serum tears four times daily. Partial tarsorrhaphy was discussed with the patient but 

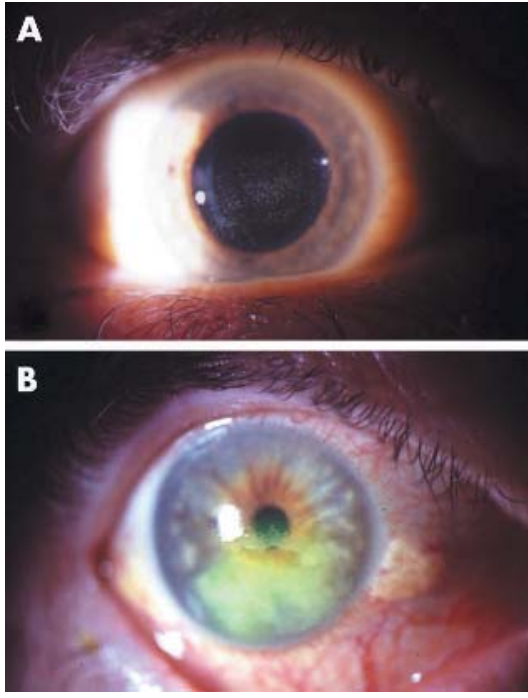

Figure 1 (A) Neurotrophic punctate epithelial keratopathy in the right eye at presentation. (B) Advanced neurotrophic keratopathy 10 weeks after initial presentation.

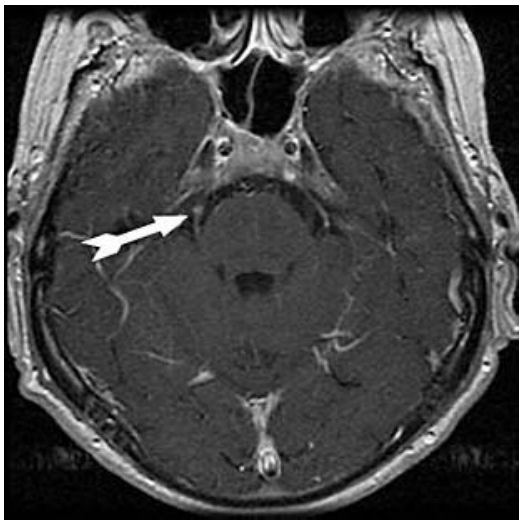

Figure 2 T2 weighted magnetic resonance imaging shows increased signal intensity in anterior aspect of right fifth nerve.

declined. During the next 6 weeks, the corneal surface improved, and at last follow up the patient's vision was 20/60.

\section{Comment}

Gamma knife radiosurgery is an effective treatment for TN with few complications. ${ }^{1-4}$ Pollock $e t a l^{6}$ noted an increased incidence of "trigeminal dysesthesia" and "corneal numbness" after high doses (90 Gy) of gamma knife radiation. In an animal model, a $100 \mathrm{~Gy}$ dose caused nerve necrosis. ${ }^{7}$ Matsuda et $a l^{5}$ identified a "dry eye complication" of epithelial keratopathy after gamma knife radiosurgery for TN. Despite these documented ocular side effects, no cases of vision loss have been reported. ${ }^{56}$

Neurotrophic keratopathy has been recognised in patients with herpes simplex, herpes zoster, and after laser in situ keratomileusis (LASIK) surgery. ${ }^{8-10}$ Mild neurotrophic keratopathy may be manifested as a punctate epithelial keratopathy. In severe cases, corneal decompensation can lead to severe vision loss.
Our patient had a vision loss to 20/200 associated with the onset of right sided facial numbness 10 months after low dose (40 Gy) gamma knife radiosurgery for TN. Although high dose radiosurgery ( $90 \mathrm{~Gy}$ ) is a known risk factor for complications with gamma knife radiosurgery, the low dose our patient received has not been associated with such complications. Patients undergoing gamma knife radiosurgery for TN should be warned of this potential complication and should be evaluated preoperatively and postoperatively by an ophthalmologist.

A Naseri Department of Ophthalmology, Mayo Clinic, Scottsdale, AZ, USA

N P Patel

Department of Neurologic Surgery, Mayo Clinic, Scottsdale, AZ, USA

Correspondence to: Dr Ayman Naseri, MD, Department of Ophthalmology, Mayo Clinic, Scottsdale, AZ 85259, USA aymannaseri@hotmail.com

doi: 10.1136/bjo.2004.045773

Accepted for publication 16 March 2004

\section{References}

1 Kondziolka D, Perez B, Flickinger JC, et al. Gamma knife radiosurgery for trigeminal neuralgia. Arch Neurol 1998;55:1524-9.

2 Pollock BE, Phuong LK, Gorman DA, et al. Stereotactic radiosurgery for trigeminal neuralgia. J Neurosurg 2002;97:347-53.

3 Regis J, Metellus P, Dufour $\mathrm{H}$, et al. Long-term outcome after gamma knife surgery for secondary trigeminal neuralgia. J Neurosurg $2001 ; 95: 199-205$.

4 Maesawa S, Salame C, Flickinger JC, et al. Clinical outcomes after stereotactic radiosurgery for idiopathic trigeminal neuralgia. J Neurosurg 2001;94:14-20.

5 Matsuda S, Serizawa T, Sato M, et al. Gamma knife radiosurgery for trigeminal neuralgia: the dry-eye complication. J Neurosurg 2002;97:525-8

6 Pollock BE, Phuong LK, Foote RL, et al. High-dose trigeminal neuralgia radiosurgery associated with increased risk of trigeminal nerve dysfunction. Neurosurgery 2001;49:58-64.

7 Kondziolka D, Lacomis D, Niranjan A, et al. Histological effects of trigeminal nerve radiosurgery in a primate model: implications for trigeminal neuralgia radiosurgery. Neurosurgery 2000;46:971-7.

8 Holland EJ, Mozayeni RM, Schwartz GS. Herpes simplex keratitis. In: Krachmer JH, Mannis MJ, Holland EJ, eds. Cornea: volume II, Clinical diagnosis and management. St Louis: Mosby, 1997:1201-2.

9 Liesegang TJ. Herpes zoster keratitis. In: Krachmer JH, Mannis MJ, Holland EJ, eds. Cornea: volume II, Clinical diagnosis and management. St Louis: Mosby, 1997:1229-30.

10 Wilson SE, Ambrosio R. Laser in situ keratomileusis-induced neurotrophic epitheliopathy. Am J Ophthalmol 2001;132:405-6.

\section{Combined aspirin and}

clopidogrel in cataract surgical patients: a new risk factor for ocular haemorrhage?

Clopidogrel (Plavix, Bristol-Myers Squibb/ Sanofi) is a thienopyridine with antiplatelet effects caused by its inhibition of ADP mediated platelet aggregation pathways. ${ }^{1}$ Both aspirin and clopidogrel have established benefits in the secondary prevention of fatal and non-fatal coronary and cerebrovascular events. ${ }^{12}$ The CURE study has concluded that combining low dose aspirin and clopidogrel in patients with acute coronary syndromes results in additional improvements in outcome over aspirin alone. ${ }^{3}$ We can therefore expect increasing numbers of ophthalmic patients who have been started on this combined treatment ("COM").

Departmental concerns were raised by experience with a 76 year old normotensive patient who was on COM. He developed progressive zonular dialysis from unexpected vitreous pressure during standard phacoemulsification. An intracapsular extraction and anterior vitrectomy were required. An iridectomy led to extensive intraoperative hyphaema and vitreous haemorrhage. Postoperative ultrasound confirmed no evidence of choroidal haemorrhage, and the vitreous blood cleared within 3 months to produce $6 / 6$ Snellen acuity with aphakic contact lens correction.

There is a lack of adequate data on the risk of surgery associated ocular bleeding with COM. Clopidogrel taken alone causes less gastrointestinal haemorrhage than aspirin, but has an otherwise similar risk profile to aspirin. $^{4}$

Post-marketing surveillance of clopidogrel has recorded "conjunctival, ocular, and retinal haemorrhage." Further information regarding these events, and whether they occurred during ocular surgery, was not available at the time of writing (Nicola Murphy, Sanofi Pharmacovigilance Department, personal communication February 2004). ${ }^{5}$ A detailed Medline literature search has produced no relevant ophthalmic case experience.

The CURE study found higher "major and minor" bleeding rates in patients taking COM compared with aspirin alone, but showed no increase in life threatening or intracranial haemorrhage, and does not record ocular haemorrhage. Of note is the significant increase in major bleeding events recorded in COM patients undergoing coronary artery bypass graft surgery where the clopidogrel was stopped less than 5 days before the procedure.

A February 2004 telephonic survey of nursing staff running cataract pre-assessment clinics at 15 ophthalmic units across the United Kingdom indicated variable approaches to such agents. Individual consultants at three units stopped clopidogrel preoperatively. Twelve units continued clopidogrel; none had specific policy for patients on aspirin and clopidogrel. The related and relevant issue of anaesthetists' approach to regional ocular anaesthesia in patients on such treatment was not addressed.

Translating the CURE study results into a "number needed to treat," approximately 47 patients with acute coronary syndrome would require treatment for 9 months with aspirin and clopidogrel to prevent one cardiovascular death, non-fatal myocardial infarction, or stroke. ${ }^{36}$ Stopping clopidogrel for a short period is therefore unlikely to make a material difference to the vascular event risk for an individual.

In summary, there is an increased risk of systemic bleeding associated with COM compared to aspirin alone. The degree of perioperative bleeding risk with elective eye surgery is still undefined. Our departmental policy has been changed to stopping clopidogrel for 1 week in patients on combination treatment given for cataract surgery, and to use a similar approach to that normally 
employed for patients taking aspirin in those on clopidogrel alone. Other departments experience with this increasingly used antiplatelet agent would be valued.

B R Davies Hull and East Yorkshire Eye Hospital, Fountain Street, Hull HU3 2JZ, UK

Correspondence to: B R Davies, Hull and East Yorkshire Eye Hospital, Fountain Street, Hull HU3 2JZ UK; bryn.d@ukonline.co.uk

doi: 10.1136/bjo.2004.045997

Accepted for publication 11 March 2004

\section{References}

1 Jneid H, Bhatt DL et al. Aspirin and clopidogrel in acute coronary syndromes. Arch Intern Med 2003;163:1145-115.

2 CAPRIE Steering Committee. A randomised, blinded, trial of clopidogrel versus aspirin in patients at risk of ischaemic events (CAPRIE). Lancet 1996:348:1329-1339.

3 The Clopidogrel in Unstable Angina to Preven Recurrent Events Trial Investigators. Effects of clopidogrel in addition to aspirin in patients with acute coronary syndromes without ST segment elevation. N Engl J Med 2001;345:494-502

4 Harker LA, Boissel J-P, et al. Comparative safety and tolerability of clopidogrel and aspirin. Drug Safety 1999;21:325-33.

5 Bristol-Myers Squibb. Plavix. Summary of product characteristics. October 2003.

6 Guyatt GH, Sackett DL, Cook DJ. Users' guides to the medical literature. II. How to use an article about therapy or prevention. $B$. What were the results and will they help me in caring for my patients? JAMA 1994;221:59-63.

\section{The role of corticosteroids in} fungal keratitis: a different view

Fungal infections of the cornea continue to be an important cause of ocular morbidity.

This report describes a situation which occurs in clinical practice in patients with misdiagnosed fungal ulcers who are treated with a combination of topical steroids and antibiotics drops. A common strategy when these patients are finally diagnosed with fungal keratitis is to switch to antifungal agents and discontinue the corticosteroids. We have recently seen two patients with fungal keratitis who demonstrated severe inflammation and corneal necrosis after the abrupt discontinuation of corticosteroids.

\section{Case 1}

A 32 year old woman with a corneal transplant in her right eye was referred for evaluation of an unresponsive corneal ulcer in her transplant. The patient had been treated with a combination of moxifloxacin $0.5 \%$ drops hourly and prednisolone $1 \%$ drops four times per day. On initial examination there was a central stromal infiltrate with an overlying epithelial defect. The infiltrate had feathery edges reminiscent of fungal infection. No cultures had been taken up to this point.

After cultures were taken the therapeutic regimen was switched to cefazolin $50 \mathrm{mg} / \mathrm{ml}$ and gentamicin $15 \mathrm{mg} / \mathrm{ml}$ while we discontinued the corticosteroids drops. The clinical picture remained relatively unchanged during the next 48 hours. The preliminary culture results revealed fungal yeasts. We then started amphotericin $0.15 \%$ drops and fluconazole by mouth but the infection worsened over the next 2 days leading to descemetocele formation and perforation; the patient underwent an emergency keratoplasty.

\section{Case 2}

A 13 year old girl who was a soft contact lens wearer was referred for evaluation of a corneal ulcer. The patient had been treated for 2 weeks with cefazolin $50 \mathrm{mg} / \mathrm{ml}$ and tobramycin $0.3 \%$ on an hourly basis, prednisolone $1 \%$ five times per day, and ketoconazole $400 \mathrm{mg}$ by mouth. On initial examination there was a diffuse central stromal infiltrate $(2 \times 3 \mathrm{~mm})$ with the presence of an endothelial plaque and hypopyon.

We performed confocal microscopy which showed hyphae characteristic of a fungal infection. After cultures were taken we modified the therapeutic regimen to fluconazole by mouth, natamycin $5 \%$ drops, cefazolin $50 \mathrm{mg} / \mathrm{ml}$, while we discontinued the steroid drops. The patient showed signs of worsening during the next 2 days; the cornea perforated and an emergency keratoplasty was performed.

\section{Comment}

The analysis of the previous cases suggests that in patients with fungal keratitis who previously received topical corticosteroids, the abrupt cessation of these agents is likely to lead to an acute rebound inflammatory reaction and even perforation.

The proper use of corticosteroids in the treatment of fungal corneal infections continues to be debated among experts. ${ }^{23}$ The controversy arises because there are two goals in the treatment of corneal infection that are inherently incompatible: (a) to rid the affected tissue of the replicating microorganisms causing the infection, and (b) to limit the degree of structural damage caused by the infectious process. ${ }^{4}$

We recommend a gradual tapering of the corticosteroids in these cases which allows for the antifungal agents to act, and the host immune mechanisms to take control of the inflammatory response. However, clinical application in patients should be determined individually in all cases.

V Peponis, J B Herz, H E Kaufman Louisiana State University, 2020 Gravier Street, Suite B, New Orleans, LA 70112, USA

Correspondence to: Dr Vasileios Peponis, Louisiana State University, 2020 Gravier Street, Suite B, New Orleans, LA 70112 , USA; pepbas@yahoo.com doi: 10.1136/bjo.2004.047423 Accepted 31 March 2004

\section{References}

1 Tomas PA. Fungal infections of the cornea. Eye 2003; 17:852-62.

2 Pineda $\mathrm{R}$, Dolhman $\mathrm{CH}$. The role of steroids in the management of acanthamoeba keratitis, fungal keratitis and epidemic keratoconjunctivitis. In Ophthal Clin 1994;34:19-31.

3 Schreiber W, Olbrisch A, Vorwerk CK, et al. Combined topical fluconazole and corticosteroid treatment for experimental Candida albicans keratomycosis. Invest Ophthalmol Vis Sci 2003;44:2634-43.

4 Stern GA Buttross M. Use of corticosteroids in combination with antimicrobial drugs in the treatment of infectious corneal disease. Ophthalmology 1991;98:847-53.

\section{Authors' qualifications and the BJO}

It is not often that journal policy is dictated by input from the readership. A notable exception to this probably occurred in the
ANZ Journal of Surgery in 2002, following a letter to the editor in 2001 addressing authors' qualifications.

In it we pointed out that journal aspirations to international recognition and increased circulation may be enhanced by having the authors' qualifications consistently published. We indicated that the qualifications of one's international colleagues, including departmental heads where one may have trained overseas, can be recognised. The educational progress of one's colleagues-for instance, a clinician's higher qualifications (for example, $\mathrm{PhD}$ ) may be determined. We pointed out that the reader can determine whether the author is in effect a qualified ophthalmologist, a resident, or still a medical student. In some parts of the world, the rivalry between optometrists and ophthalmologists may be highlighted by one group publishing in the other's journal. Thus, qualifications may be used to discriminate between the two groups. Where the qualification discriminates between physicians and surgeons, this too can be recognised. In these days of enhanced medicolegal confrontation, a medical practitioner's viewpoint can be differentiated from that of a lawyer.

Finally, we pointed out that if the author qualifications are designated, the reader may be quite sure that the article was not written by the medical records librarian, let alone the hospital trolley boy in a moment of inspiration.

We have observed that in recent issues of the $B J O$, there appears to be an inconsistent approach to appending qualifications. Only the corresponding author is liable to be given a qualification; the first author usually goes without. For example in volume 88 number 5 (May 2004), in the perspective, only the corresponding author, Azuara-Blanco writing on cannabinoids and glaucoma received a qualification.

In the extended reports, only Miyamoto on oil droplets in rabbits, Shaarawy on day one intraocular pressure, Orgul on blood flow in glaucoma, and Probst on fibronectin in diabetes received recognition. This means that the authors of all the other extended reports missed out. In other words, in this issue of the journal, only one third of the corresponding authors, let alone the coauthors of extended reports, are given their qualifications. No one in the letters section was designated with a qualification. None of the three editorial writers received a qualification. We are left wondering as to whether Professor König, writing on the cost effectiveness of treatment for amblyopia, was a paediatric ophthalmologist branching out into community medicine, a medical politician, a health economist, a statistician, or a psychotherapist having a different weekend. Whatever he is, he reached a reassuring conclusion in his article, that amblyopia therapy is "likely to be very cost effective.", We also do not know whether Schwab, writing about the cover illustration "Halcyon days," with the university affiliation of UC Davis, was an artist, the university photographer, an ornithologist, an anthropologist, or a Greek mythologist. ${ }^{3}$ In the article on postoperative leak in trabeculectomy, Henderson can be recognised as a surgeon by the British appellation "Mr." We thus presume he has an FRCS or an FRCOphth, but we don't really know.

Our point is made. As we demonstrated in our original article, ${ }^{1} 89.5 \%$ of the 19 journals regularly read by us use author qualifications. 
A journal of the integrity, breadth, and currency of the BJO should, in our view, append author qualifications in 2004 .

D Papalkar, I C Francis

Department of Ophthalmology, Prince of Wales Hospital, Randwick, Sydney, Australia

Correspondence to: Dr lan C Francis, Suite 12 Chatswood Grove, 12-14 Malvern Avenue, Chatswood NSW 2067, Australia; if@student.unsw. edu.au

doi: 10.1136/bjo.2004.050419

Accepted for publication 17 June 2004

\section{References}

1 Francis IC. ANZ journal of surgery: authors' qualifications. ANZ J Surg 2001;71:382.

2 König H-H, Barry J-C. Cost effectiveness of treatment for amblyopia: an analysis based on a probabilistic Markov model. Br J Ophthalmol 2004:88:606-12.

3 Schwab IR, Hart NS. Halcyon days.

Br J Ophthalmol 2004:88:613.

\section{MAILBOX}

\section{Mohs surgery: efficient and effective}

We read with interest the report of Hsuan et al. ${ }^{1}$ The authors present a case series of 55 patients with basal cell carcinoma on the eyelids. There are no details regarding the size or histological subtypes of basal cell carcinoma in the results and therefore it is difficult to assess the applicability of the results to other groups of patients who may have more or less severe basal cell carcinoma The authors make several generalisations regarding Mohs surgery that we believe are unsubstantiated and we wish to take the opportunity to clarify a few points.

The essence of Mohs micrographic surgery is $100 \%$ histological frozen section margin control. There is no other technique that enables $100 \%$ margin examination, including the authors' bread loaf section technique. Mohs micrographic surgery has 99\% 5 year cure rates for basal cell carcinoma because of the thorough margin examination. In distinction, standard bread loaf section technique examines approximately $0.1 \%$ of the surgical margin, with an increased potential to miss infiltrative tumour extensions. Because the bread loaf technique is least likely to accurately detect a positive margin, many surgeons employ a tangential peripheral section analysis as a means of obtaining more thorough examination of the margin.

Mohs micrographic surgery has another advantage, which is true tissue sparing. The margin of normal skin removed during Mohs micrographic surgery may be as little as $0.5 \mathrm{~mm}$. When operating on the eyelid, $1 \mathrm{~mm}$ can be the difference between sacrifice and preservation of a critical structure (that is, punctum). The authors sacrificed $2 \mathrm{~mm}$ on both sides of the skin cancer, which in some cases may have resulted in up to $3 \mathrm{~mm}$ of unnecessary skin removal. This could result in more complicated reconstruction for patients.

The authors state that their patients were happy to have multiple operative sessions For patients undergoing Mohs micrographic surgery, complete tumour removal is accomplished in one session, with reconstruction performed on the same day as tumour extirpation. The inconvenience to patients associated with staged re-excision after 48 hours of histological examination and then a final stage reconstruction 48 hours after the last histological sample is taken should not be underestimated. Patients in general are pleased with their care based primarily with their interaction with the physicians. However, I sincerely doubt that any patient would choose three surgical interventions over 5 days rather than one surgical intervention with $100 \%$ margin control in 1 day.

The authors state that Mohs surgery is "too expensive." This statement is unsubstantiated. In a cost analysis by Cook and Zitelli, ${ }^{2}$ Mohs surgery was found to be similar in cost to excisional surgery and less expensive than frozen section analysis. With three potential operative encounters, the cost of staged excision of basal cell carcinoma in the United States would exceed that for Mohs micrographic surgery with reconstruction on the same day. It is also important to note that the pathological charges are included in the Mohs surgery fee, as the Mohs surgeon functions as both the surgeon and pathologist. Therefore, pathology charges generated for multiple staged re-excisions must be included in any calculation of cost associated with staged excision.

The authors characterised Mohs surgery as "laborious." I would argue that one doctor performing a very efficient tissue sparing operation all in a matter of 2-4 hours, a typical duration for Mohs surgery and reconstruction, with the pathology included within that time frame and fee, is both cost efficient and labour efficient. Mohs surgery has been especially designed for accuracy, tissue sparing, convenience, cost efficiency, and labour efficiency.

Mohs surgeons are expert in the complete removal of complex skin cancers, particularly on the central facial area. Mohs surgeons work closely with our colleagues in oculoplastic surgery in the United States to coordinate expert reconstruction of the resultant defects. In places where Mohs surgery is less available, close communication between the surgeon and pathologist, and tangential vertical margin processing may offer a reasonable therapeutic option, although one that is more inconvenient, costly, and laborious for patients and physicians alike.

\section{C Otley}

Mayo Clinic, 2201 st Street SW Rochester, MN 55905, USA; otley.clark@mayo.edu

S J Salasche American College of Mohs Micrographic Surgery and Cutaneous Oncology

doi: $10.1136 /$ bjo. 2004.047068

Accepted 19 March 2004

\section{References}

1 Hsuan JD, Harrad RA, Potts MJ, et al. Small margin excision of periocular basal cell carcinoma: 5 year results. $\mathrm{Br} J$ Ophthalmol carcinoma: 5 year

2 Cook J, Zitelli J. Mohs micrographic surgery: a cost analysis. J Am Acad Dermatol 1998:39:698-703.

\section{Macular infarction after intravitreal amikacin: authors' reply}

We thank Doft et al for their useful and expert opinion. ${ }^{1}$ The choice of which agent to use to empirically treat Gram negative organisms implicated in endophthalmitis remains controversial. As amikacin has been proved to cause macular infarction, we think one should look at viable alternatives. Ceftazidime is already in widespread use in the United Kingdom and appears not only to have an excellent safety profile but also good clinical effect. Unfortunately, until we have proper in vivo and in vitro "head to head" comparison studies, it is difficult to know which is the more efficacious agent. As far as synergism is concerned, vancomycin and ceftazidime are usually not tested together because vancomycin acts on Gram positive organisms and ceftazidime is used primarily for Gram negative infections. However, there is one study that reported synergy between vancomycin and ceftazidime against Gram positive organisms. ${ }^{2}$

The study by Kwok and colleagues raises a concern that ceftazidime precipitation, as assessed by in vitro studies, may affect its action in vivo. ${ }^{3}$ The authors of our study have noticed temporary precipitants in vivo without apparent alteration of clinical effect (AR). Previous animal models do show that ceftazidime reaches intravitreal minimal inhibitory concentrations for common Gram negative microbes after a single intravitreal injection. ${ }^{4}$ Perhaps assay at the time of repeat injection, non-invasive confocal Raman spectroscopy of the anterior chamber, or further animal models may provide additional insight into ceftazidime pharmacokinetics and the phenomenon of ceftazidime precipitation so as to guide future therapeutic choice. Ultimately the decision lies with the treating surgeon, who should be aware of both the efficacy and safety profiles of the agents available. We still believe, with the evidence presented in our article, ${ }^{5}$ that ceftazidime currently represents the best agent for the treatment of Gram negative microbes in endophthalmitis.

G D Galloway, A Ramsay, K Jordan, A Vivian Addenbrooke's Hospital, Cambridge, UK

Correspondence to: G D Galloway, Addenbrooke's Hospital, Cambridge, UK; gavgal@doctors.net.uk

doi: 10.1136/bjo.2004.042838

Accepted 22 January 2004

\section{References}

1 Doft BH, Barza H. Macular infarction after intravitreal amikacin. Br J Ophthalmol 2004;88:850.

2 Simon C, Littschwager $G$. In vitro activity of ceftazidime in combination with other antibiotics. Infection 1985;13:184-9

3 Kwok AK, Hui $M$, Pang $C P$, et al. An in vitro study of ceftazidime and vancomycin concentrations in various fluid media: implications for use in treating endophthalmitis. Invest Ophthalmol Vis Sci 2002;43: 1182-8

4 Mochizuki K, Yamashita Y, Torisaki M, et al. Intraocular kinetics of ceftazidime (Modacin). Ophthalmic Res 1992;24:150-4.

5 Galloway G, Ramsay A, Jordan K, et al. Macular infarction after intravitreal amikacin: mounting evidence against amikacin. $\mathrm{Br} J$ Ophthalmol 2002;86:359-60.

\section{LASIK in children?}

O'Keefe and Nolan report on LASIK surgery in five children with unilateral high myopia who were presumed to have amblyopia. ${ }^{1}$ One subject had bilateral high myopia. 
Optic nerve hypoplasia is associated with high myopia. In addition, anisometropic myopia is a common sequela of retinopathy of prematurity. Thinning of the sclera with posterior staphyloma formation has long been known to be associated with high myopia. Best corrected visual acuity in these patients is often limited by associated retinal and scleral pathology.

None of the treated eyes obtained acuity better than 6/15. This limited outcome following refractive surgery may be because optical enlargement of the retinal image rather than enhanced neurosensory function. In the three children who were less than 3 years old improved literacy, familiarity with the test procedure, and the Hawthorn effect were certainly important factors in their assumed improvement. The absolute lack of progress in one child was a probable manifestation of pre-existing retinal pathology rather than non-compliance with patching. ${ }^{2-}$

The authors advocate increased use of LASIK to thin the corneas of highly myopic children who already have profound reductions in scleral thickness. "From a clinical viewpoint, optic nerve hypoplasia should be carefully looked for in all patients with unilateral bilateral high myopia and visual loss." ${ }^{\prime \prime}$ It may well be more appropriate to improve the quality of retinal and optic nerve evaluations before performing irreversible surgical procedures with unknown long term consequences for these abnormal eyes.

P Lempert

Cornell University, School of Veterinary Medicine 10 Brentwood Drive, Ithaca, NY 14850, USA eyechartplus@aol.com

doi: 10.1136/bjo.2004.042853

Accepted for publication 22 January 2004

\section{References}

O'Keefe M, Nolan L. LASIK surgery in children. Br J Ophthalmol 2004;88:19-21.

2 Avery H Weiss, Eric A ROS. Axial myopia in eyes with optic nerve hypoplasia. Graefes Arch Clin Exp Ophthalmol 1992;230:372-7.

3 McBrien NA, Gentle A. Role of the sclera in the development and pathological complication of myopia. Progr Ret Eye Res 2003;22:307-38.

4 Wickstrom G, Bendix T. "Hawthorne effect" what did the original Hawthorne studies actually show? Scand J Work Environ Health 2000;26:363-7

5 Lied TR, Kazandjian VA. A Hawthorne strategy: implications for performance measurement and improvement. Clin Perform Qual Health Care 1998;6:201-4

\section{CORRECTIONS}

doi: 10.1136/bjo.2003.035931.corr

In the paper titled The severe acute respiratory syndrome coronavirus in tears $(\mathrm{Br} J$ Ophthalmol 2004;88:861-863) H-N Leong was not listed as an author. The authors should have been listed as, S-C Loon, S C B Teoh, L L E Oon, S-Y Se-Thoe, A-E Ling, Y-S Leo and $\mathrm{H}-\mathrm{N}$ Leong. The journal apologises for this error.
In the letter titled Prospective case control study on genetic association of apoliprotein $\epsilon 2$ with intraocular pressure $(\mathrm{Br} \mathrm{J}$ Ophthalmol 2004;88:581-582) the authors were listed incorrectly. The correct listing is as follows: A Jünemann, S Bleich, U Reulbach, K Henkel, N Wakili, G Beck, B Rautenstrauss, C Mardin, G O H Naumann, A Reis, J Kornhuber. The journal apologises for this error.

\section{NOTICES}

\section{4th International Congress on Autoimmunity}

The 4th International Congress on Autoimmunity will take place 3-7 November 2004 in Budapest, Hungary. The deadline for the receipt of abstracts is 20 June 2004. Further details: Kenes International Global Congress Organisers and Association Management Services, 17 Rue du Cendrier, PO Box 1726, CH-1211 Geneva l, Switzerland (tel: +41 22908 0488; fax: +41 22732 2850; email: autoim04@kenes.com; website: www.kenes. com/autoim2004)

\section{International Congress for Eye Research}

The XVI International Congress for Eye Research will be held on 29 August 3 September 2004 in Sydney, Australia. For further information, please contact: icer2004@tourhosts.com.au (website: www. tourhosts.com.au/icer2004)

\section{Ophthalmic Anesthesia Society}

The $18^{\text {th }}$ Annual Meeting of the Ophthalmic Anesthesia Society will be held on $1-3$ October 2004 in Chicago, USA. For further details: Ophthalmic Anesthesia Society (OAS), 793-A Foothill Blvd, PMB \#119, San luis Obispo, CA 93405 USA (tel: 001 805534 0300; fax: 001805534 9030; email: info@eyeanesthesia.org; website: www.eyeanesthesia.org).

\section{Glaucoma Society Silver Jubilee Meeting 2004}

The Silver Jubilee Meeting and Dinner for the Glaucoma Society will be held on 3 December 2004 at the Royal College of Physicians in Regents Park, London. The meeting will take place between $8.30 \mathrm{am}$ and $5 \mathrm{pm}$ and the dinner will be held between 6.30pm and $10 \mathrm{pm}$. For further information, please contact: Janet Flowers, Administrator, 29 Quarry Hill, Grays, Essex, RM17 5BT (tel: 01375 383172; e-mail: glausoc@ukeire.freeserve. co.uk).

\section{Amsterdam Retina Debate}

The Amsterdam Retina Debate will be held on 10 December 2004 at the Academic Medical Centre, Amsterdam, The Netherlands. For further information, please contact: Nicolaes Tulp Institute; tel: +31 20566 8585; fax: +31 20696 3228; email: retinadebate@amc. uva.nl

\section{Sunshine Fund for Blind Children}

The Royal National Institute of the Blind are permanently in great need of new, used, foreign, British and all other kinds of postage stamps. The stamps are sold to raise money for children in need of specially adapted toys and everyday gadgets, holidays, help for parents and the any other needs of blind and partially sighted children throughout the UK. Please send stamps (British and foreign stamps should be sent in separate envelopes) to the following address: RNIB, PO Box 6198 , Leighton Buzzard, LU7 9XT.

\section{Prestigious Helen Keller Foundation prize awarded to one of London's most eminent ophthalmologists}

Professor Alan Bird, Institute of Ophthalmology, University College London and Consultant Ophthalmologist at Moorfields Eye Hospital NHS Trust, has been awarded one of ophthalmology's most prestigious prizes, the Helen Keller Prize for Vision Research. The prize was created in 1994 by the Helen Keller Foundation for Research and Education, based in the USA, and honours the scientists and researchers working in the field of blindness and visual loss. Professor Bird is one of the world's leading experts on age related macular degeneration (AMD), inherited macular degeneration and Retinitis Pigmentosa (RP), and has led research into the identification of the genes which cause retinal degeneration. As well as his scientific research, Professor Bird also continues to treat patients at regular clinics at Moorfields Eye Hospital. Further information on Moorfields is available at: www. morrfields.nhs.uk. Further information about the Helen Keller Foundation is available at www.helenkellerfoundation.org. Further information on the Institute of Ophthalmology is available at www.ucl.ac.uk/ioo.

\section{Sophie sees sight saving projects in Tanzania with VISION 2020}

HRH The Countess of Wessex has recently returned from a trip to Tanzania in her role as Patron of VISION 2020: The Right to Sight. Throughout the trip The Countess met with representatives of and visited projects supported by VISION 2020 Partners, including Sight Savers International (SSI), Christian Blind Mission (CBM), International Eye Foundation, International Trachoma Initiative (ITI), Helen Keller International (HKI), International Centre for Eye Education (ICEE), the SEVA Foundation and the Kilimanjaro Centre for Community Ophthalmology (KCCO). VISION 2020: The Right to Sight is a global initiative of the International Agency for the Prevention of Blindness (IAPB) and the World Health Organization (WHO), with a coalition of international Non-Governmental organisations. VISION 2020 aims to eliminate unnecessary blindness in order to give all people in the world, particularly the millions of needlessly blind, The Right to Sight. For further information, please visit www.v2020.org. 